
S. Wellens, R. Goovaerts, C. Möller,
J. Luyten,
B. Thijs, K. Binnemans
Green Chemistry 15, 3160-3164 (2013)

Cite this: DOI: $10.1039 / \mathrm{c0xx} 00000 x$

www.rsc.org/XXXXXX

COMMUNICATION

\title{
Continuous ionic liquid extraction process for the separation of cobalt from nickel
}

\author{
Sil Wellens, ${ }^{a, b}$ Remi Goovaerts, ${ }^{b}$ Claudia Möller, ${ }^{b}$ Jan Luyten, ${ }^{b}$ Ben Thijs ${ }^{b}$ and Koen Binnemans ${ }^{* a}$ \\ Received (in $X X X, X X X) X$ th $X X X X X X X X X 20 X X$, Accepted Xth $X X X X X X X X X 20 X X$ \\ ${ }_{5}$ DOI: 10.1039/b000000x
}

A continuous ionic liquid extraction process using the ionic liquid trihexyl(tetradecyl)phosphonium chloride (Cyphos ${ }^{\circledR}$ IL 101) has been developed for the selective extraction of cobalt from nickel. The performance of this continuous extraction ${ }_{10}$ process is competitive with that of currently applied industrial processes, but the elimination of volatile odorous compounds from the extraction phase leads to environmentally friendlier and healthier working conditions.

\section{Introduction}

15 Solvent extraction is one of the major hydrometallurgical techniques for the separation and purification of metals. ${ }^{1}$ This technique has gained interest because it is possible to operate it in a continuous mode, with a high throughput and relatively simple equipment. In metal separation via solvent extraction a water20 immiscible phase (extraction phase) is mixed with an aqueous solution containing metal ions. The metal ions are distributed between the two phases and the extraction phase is selectively enriched with one or more metals. The extraction phase contains three main components: an extractant, modifiers and a diluent.

${ }_{25}$ The extractant is the active species which transfers the metal ions between the two phases. Modifiers are added in order to improve the properties of the extraction phase. The diluent is an organic solvent, such as kerosene, dodecane, toluene, dichloromethane and diethyl ether, capable of dissolving the extractant. These 30 solvents are toxic, flammable and/or volatile so that replacement of these volatile organic solvents with environmentally friendlier alternatives is a high priority, given the growing awareness of safety and environmental issues. Ionic liquids (ILs) are a possible alternative for the volatile solvents in the extraction phase, 35 because ionic solvents are non-volatile and non-flammable. ${ }^{2,3}$ Ionic liquids offer possibilities to make hydrometallurgical process environmentally friendlier, ${ }^{4,5}$ and they have been investigated intensively for the extraction of metal ions. ${ }^{6-13}$ However, it has been shown that the ionic liquid anions and/or 40 cations can be lost to the aqueous phase via an ion exchange mechanism. ${ }^{14-16}$ This makes the practical implementation of ionic liquids in solvent extraction difficult, both from an economical and environmental point of view. Recently, we developed a more environmentally friendlier approach for the use of ionic liquids in 45 solvent extraction processes, by a non-fluorinated ionic liquid playing the role of both the extractant and diluent. ${ }^{17}$ More particularly, cobalt was selectively extracted from nickel present in an aqueous phase by using the ionic liquid trihexyl(tetradecyl)phosphonium chloride as extraction phase, 50 eliminating the volatile and flammable character of the extraction phase. This extraction system was also applied to the separation of iron from neodymium and of cobalt from samarium. ${ }^{18}$ These separations are relevant to recycling of rare earths from permanent magnets. ${ }^{19}$

55 It has been stated that the use of ionic liquids without diluents in solvent extraction processes is not practical at all, because of the high viscosity of the ionic liquid phase..$^{20}$ However, in this Communication, we demonstrate that a continuous solvent extraction process for the separation of cobalt from nickel is 60 possible using ionic liquids without organic diluents and that it could be competitive with current industrially applied processes after minor optimizations. To the best of our knowledge, the use of ionic liquids without organic diluents in a continuous solvent extraction process has not been described in the literature yet.

\section{${ }_{65}$ Experimental}

\section{Chemicals}

Trihexyl(tetradecyl)phosphonium chloride ( > 97\%) $\left(\mathrm{Cyphos}^{\circledR} \mathrm{IL}\right.$ 101) was purchased from Cytec Industries Inc. (Niagara Falls, Ontario, Canada). $\mathrm{CoCl}_{2} \cdot 6 \mathrm{H}_{2} \mathrm{O}$ and $\mathrm{NiCl}_{2} \cdot 6 \mathrm{H}_{2} \mathrm{O}$ (> 99\%) were 70 obtained from VWR (Leuven, Belgium). Hydrochloride solutions were prepared from $\mathrm{HCl}$ (Selectipur VLSI, 36\% BASF) and demineralised water. All chemicals were used as received, without further purification.

\section{Instrumentation and methods}

75 The metal contents of the aqueous and organic phases after extraction for the batch scale experiments were determined using ICP-OES (Varian Vista Pro). The chloride content was determined by potentiometrical titration with $\mathrm{AgNO}_{3}$. The total carbon content (TOC) was measured using a Shimadzu TOC${ }_{80}$ VWP TOC analyzer. The sample preparation has been described earlier. ${ }^{17}$ Peristaltic pumps (Gilson minipuls 3) (P1, P2, P4) and a plunger pump (CAT Labo pump - HPLH 200) (P3) were used to pump the solutions.

\section{Experimental Set up}

${ }_{85} 15 \mathrm{~L}$ of a synthetic aqueous feed solution of $\mathrm{Co}$ (II) and $\mathrm{Ni}$ (II) with a metal concentration of $5 \mathrm{~g} \mathrm{~L}^{-1}$ for both metals was prepared from $\mathrm{CoCl}_{2} \cdot 6 \mathrm{H}_{2} \mathrm{O}$ and $\mathrm{NiCl}_{2} \cdot 6 \mathrm{H}_{2} \mathrm{O}$ in $7.6 \mathrm{M} \mathrm{HCl}$. The ionic 
liquid Cyphos ${ }^{\circledR}$ IL 101 (7 L) was presaturated with water (approximately $14 \mathrm{wt} \%$ ) in order to keep the volume ratio of the phases constant and to decrease the viscosity of the ionic liquid phase. The ionic liquid feed was kept at a temperature of $60{ }^{\circ} \mathrm{C}$. ${ }_{5}$ Five mixer-settler reactors $(2.8 \mathrm{~L})$ were placed in series (Figure 1). The first reactor was filled with $1.25 \mathrm{~L}$ of cobalt-nickel feed, while all the other mixers were filled with $1.25 \mathrm{~L}$ of water. The ionic liquid was pumped $\left(\mathrm{P}_{2}\right)$ into the first reactor $\left(\mathrm{MS}_{1}\right)$ at a flow rate of $15 \mathrm{~mL} \mathrm{~min}^{-1}$, while the phases were mixed. As soon as the 10 reactor was filled, the aqueous feed solution was separately pumped $\left(\mathrm{P}_{1}\right)$ into the first mixer settler reactor at a flow rate of 14 $\mathrm{mL} \min ^{-1}$. The start-up principle was maintained in a similar way for all other mixer-settlers. In the second reactor $\left(\mathrm{MS}_{2}\right)$, the pregnant ionic liquid was washed by pumping water $\left(\mathrm{P}_{4}\right)$ through 15 it at a flow rate of $5.6 \mathrm{~mL} \mathrm{~min}{ }^{-1}$. In the following three mixers settlers $\left(\mathrm{MS}_{3-5}\right)$ the cobalt was stripped in counter current with water at a flow rate of $11.5 \mathrm{~mL} \mathrm{~min}^{-1}\left(\mathrm{P}_{3}\right)$. All reactors were stirred at $700 \mathrm{rpm}$ and the temperatures in the reactors were kept constant at $50{ }^{\circ} \mathrm{C}$, using a heat-conducting ribbon. After 16 hours 20 of circulation, the water phase was analysed for the cobalt, nickel, chloride and TOC content. The ionic liquid phase was analysed for the cobalt and nickel content.

\section{Results and discussion}

Trihexyl(tetradecyl)phosphonium chloride, commercially 25 known as Cyphos ${ }^{\circledR}$ IL 101, was selected as the extraction phase, both acting as solvent and extractant for the selective extraction of cobalt from nickel in chloride media, because of its specific properties: hydrophobic character, a melting point below room temperature, commercial availability, and the absence of 30 fluorinated anions. ${ }^{21}$ This makes Cyphos ${ }^{\circledR}$ IL 101 an easily manageable, relatively cheap and environmentally friendly ionic liquid, which is suitable for use on an industrial scale. In an aqueous phase with high chloride concentrations, cobalt(II) will be present as an anionic tetrachlorocobaltate(II) complex (blue), 35 whereas nickel(II) will be present as the hexaaquo complex (green). The anionic tetrachlorocobaltate(II) complex is extracted to the ionic liquid phase, while the hydrated nickel(II) ion stays in the aqueous phase making it possible to separate cobalt from nickel with Cyphos $^{\circledR}$ IL 101. The back extraction (or stripping) of 40 cobalt from the ionic liquid is possible with water; water lowers the electrolyte concentration forcing cobalt to reform a hexaaquo complex (pink).

The high viscosity of Cyphos $^{\circledR}$ IL 101 (about $2500 \mathrm{cP}$ at $\left.20^{\circ} \mathrm{C}\right)^{21}$ made the implementation in a continuous extraction 45 process challenging. Both presaturating the ionic liquid with water and heating up the ionic liquid up to $60{ }^{\circ} \mathrm{C}$ reduced its viscosity (to about $100 \mathrm{cP})^{17}$ and made it manageable to transfer the highly viscous liquid through pumping. The experimental setup and all selected extraction parameters were carefully chosen 50 on the basis of our previous work on the cobalt-nickel separation in a batch process. ${ }^{17}$ The actual setup is shown in Figure 1 and the schematic representation of the continuous extraction process is shown in Figure 2. The cobalt extraction takes places in the first reactor $\left(\mathrm{MS}_{1}\right)$, leaving nickel in the aqueous raffinate. A close-up 55 of the first reactor is shown in Figure 3. The ionic liquid loaded with cobalt is then washed in the second reactor $\left(\mathrm{MS}_{2}\right)$ and in the last three stages $\left(\mathrm{MS}_{3}\right.$ to $\left.\mathrm{MS}_{5}\right)$ cobalt is stripped from the ionic liquid solutions using water in counter-current mode, forming the cobalt raffinate. The regenerated ionic liquid is directly fed back 60 to $\mathrm{MS}_{1}$ to extract a new load of cobalt.

After 16 hours of continuous cycling, the cobalt and nickel concentrations of the different aqueous streams were analysed (Table 1). It can be seen that the nickel raffinate contained only $21 \mathrm{ppm}$ of cobalt, giving rise to a nickel purity of $>99.5 \%$. The 65 removal of the residual cobalt impurities is discussed further in the text. After the washing stage, which was introduced to reduce the chloride content of the ionic liquid phase, the wash water contained small amounts of cobalt and nickel. These losses could be prevented by recycling the wash water back to the extraction 70 circuit. The cobalt raffinate with a low nickel impurity level had a cobalt purity of $>99.8 \%$. Nearly all cobalt was removed from the ionic liquid phase after passing through three stripping stages.

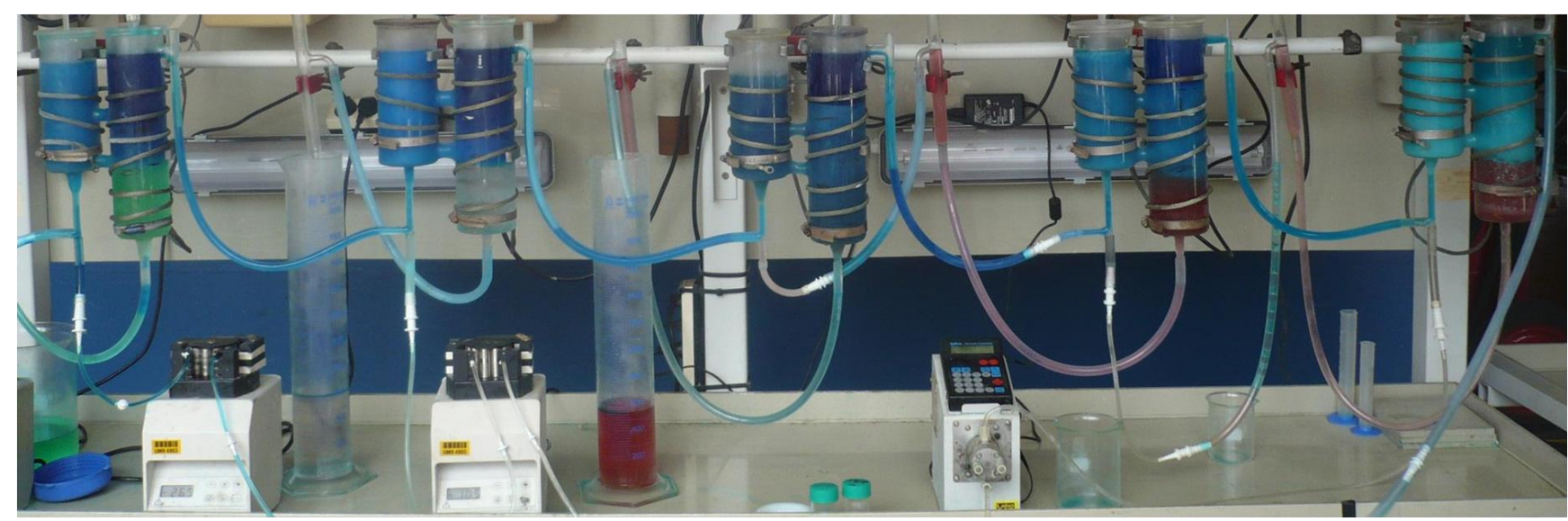

Figure 1: Operational continuous extraction process for the separation of cobalt from nickel with the trihexyl(tetradecyl)phosphonium chloride ionic 75 liquid (Cyphos ${ }^{\circledR}$ IL 101) as extraction phase. The different steps are (from left to right): extraction step, washing step and three stripping steps in countercurrent mode. 


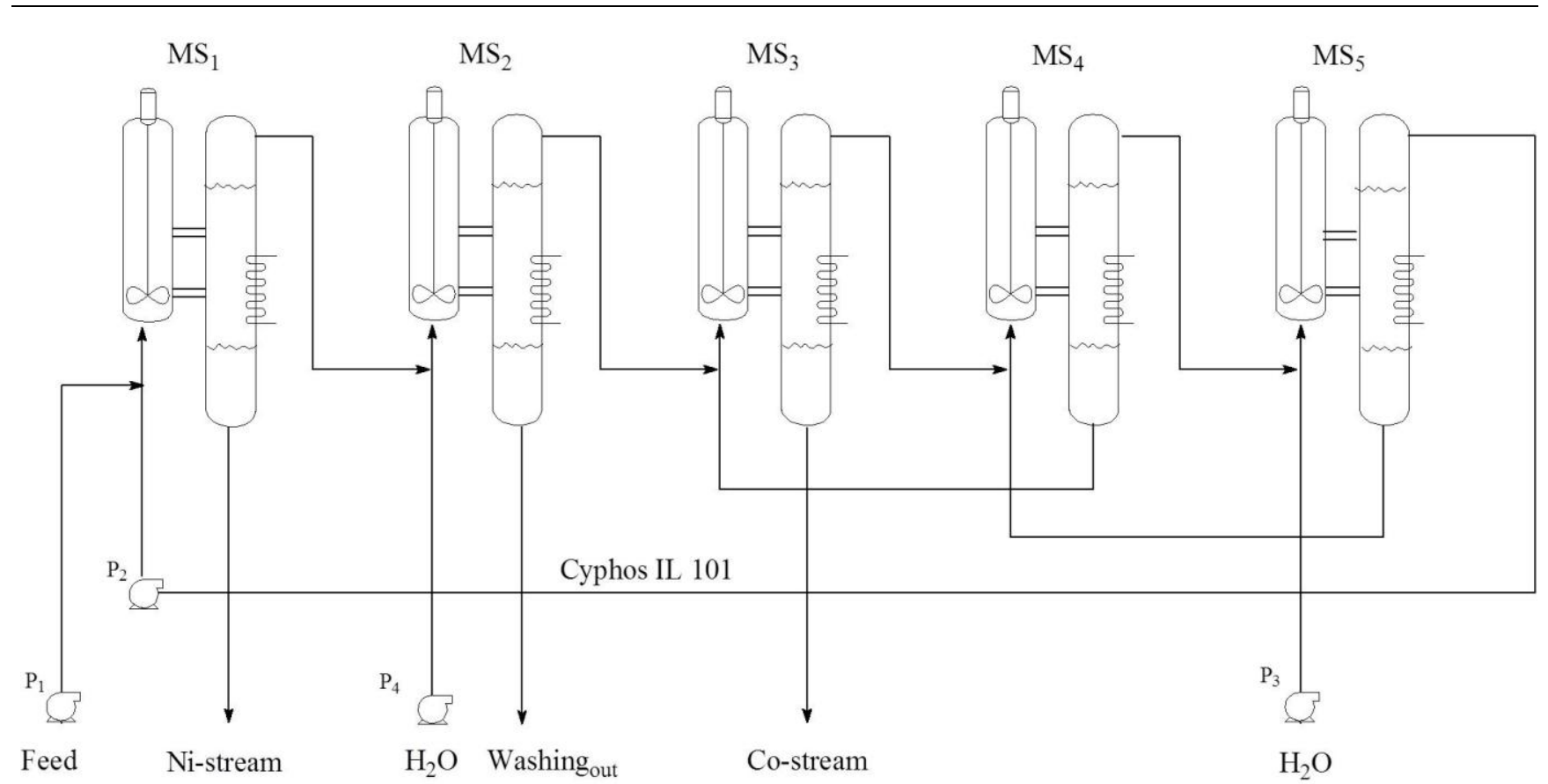

Figure 2: Schematic representation of the continuous ionic liquid extraction process using the ionic liquid trihexyl(tetradecyl)phosphonium chloride, Cyphos ${ }^{\circledR}$ IL 101; (MS = mixer-settler; $\mathrm{P}=$ pump).

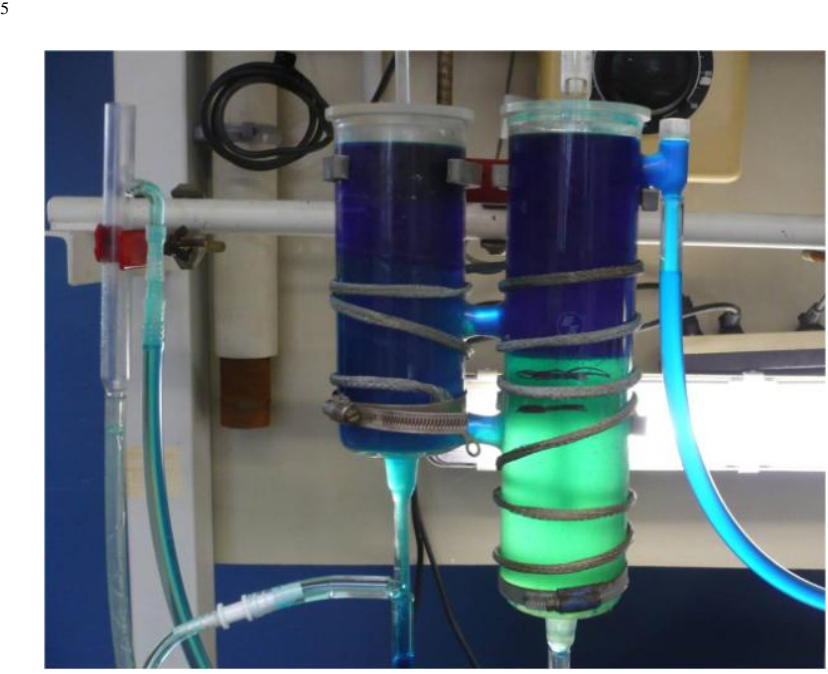

Figure 3: Close-up of the first mixer-settler ( $\mathrm{MS}_{1}$, not operational) in which the cobalt extraction takes place: mixing compartment (left) and 10 phase-settling compartment (right).

A remark about the chloride contents before and after $\mathrm{MS}_{1}$ has to be made: the aqueous feed had a chloride content of $7.6 \mathrm{M}$, whereas the chloride concentration in the nickel raffinate was 15 only $6.4 \mathrm{M}$. This is because the ionic liquid that is used as the input in $\mathrm{MS}_{1}$ originated from the after-stripping stage at $\mathrm{MS}_{5}$. Due to the different stripping stages, the ionic liquid at this point was saturated with water. The chloride ions in the aqueous feed redistributed into the ionic liquid and decreased the chloride 20 concentration of the aqueous phase by $14 \%$. Since the distribution ratio of cobalt depends on the chloride concentration, this dilution effect also decreases the extraction efficiency of cobalt. ${ }^{17}$
Further optimisation of the process is possible by using a pretreatment step to increase the chloride concentration of the ionic 25 liquid outlet stream of $\mathrm{MS}_{5}$. Pretreatment of the outlet stream with the nickel raffinate, which has a $6.4 \mathrm{M}$ chloride concentration, has two beneficial effects: (1) it will increase the chloride concentration of the ionic liquid stream; (2) removal of the cobalt impurities present in the nickel raffinate will lead to a 30 purer nickel solution. This pretreatment is equivalent to two mixer-settlers in counter-current mode.

Reagent losses from the extraction phase to the aqueous phase are inherent to solvent extraction processes. Typical losses during an extraction processes for tertiary amines in acidic media are 35 between 10 and $40 \mathrm{ppm}^{22}$ In our extraction process, the loss of the phosphonium cation to the different aqueous streams was ranging from 40 to $80 \mathrm{ppm}$. These losses are thus comparable to the current state-of-the-art. However to further reduce the loss of ionic liquid cation in the aqueous phase, a salting-out process 40 could be used, ${ }^{23}$ and the ionic liquid could be recovered by nanofiltration. $^{24,25}$

Table 1: Cobalt, nickel, chloride and phosphonium cation concentrations in the different aqueous streams and in the ionic liquid outlet stream.

\begin{tabular}{ccccc}
\hline & $\begin{array}{c}\mathrm{Co} \\
\left(\mathrm{mg} \mathrm{L}^{-1}\right)\end{array}$ & $\begin{array}{c}\mathrm{Ni} \\
\left(\mathrm{mg} \mathrm{L}^{-1}\right)\end{array}$ & $\begin{array}{c}\mathrm{Cl}^{-} \\
(\mathrm{M})\end{array}$ & $\begin{array}{c}{\left[\mathrm{P}_{66614}\right]^{+}} \\
\left(\mathrm{mg} \mathrm{L}^{-1}\right)\end{array}$ \\
$\begin{array}{c}\text { Feed } \\
\text { Ni raffinate } \\
\left(\mathrm{MS}_{1}\right)\end{array}$ & 5000 & 5000 & 7.6 & $--{ }^{a}$ \\
$\begin{array}{c}\text { Wash water } \\
\left(\mathrm{MS}_{2}\right)\end{array}$ & 21 & 4900 & 6.4 & 43 \\
$\begin{array}{c}\text { Co raffinate } \\
\left(\mathrm{MS}_{3}\right)\end{array}$ & 5000 & 100 & 2.8 & 42 \\
$\begin{array}{c}\mathrm{IL} \mathrm{outlet}^{\left(\mathrm{MS}_{5}\right)} \\
(55\end{array}$ & 7 & 0.8 & 77 \\
\end{tabular}

$45^{a}$--- $=$ not measured; n.d. $=$ not detected 
The separation of cobalt and nickel by solvent extraction from chloride media is on an industrial scale applied by Xstrata Nikkelverk, (Kristiansand, Norway), Sumitomo Metal Mining 5 (Niihama, Japan) and Eramet (Le-Havre-Sandouville, France). ${ }^{26}$ The Xstrata Nickelverk plant uses tri-isooctylamine as extractant diluted in $17 \%$ of aromatic diluents. ${ }^{27}$ The process makes use of four mixer-settlers in a counter-current mode to extract cobalt from the leach solution, several small mixer-settlers for the 10 removal of nickel impurities and two mixer settlers for stripping of cobalt. The leach solution used as feed contains $220 \mathrm{~g} \mathrm{~L}^{-1}$ nickel and $11 \mathrm{~g} \mathrm{~L}^{-1}$ cobalt. After extraction, a nickel-rich solution of $60 \mathrm{~g} \mathrm{~L}^{-1} \mathrm{Ni}$ and $0.03 \mathrm{~g} \mathrm{~L}^{-1} \mathrm{Co}$, and a cobalt-rich solution of $0.01 \mathrm{~g} \mathrm{~L}^{-1} \mathrm{Ni}$ and $50 \mathrm{~g} \mathrm{~L}^{-1} \mathrm{Co}$ are obtained. The ionic liquid 15 continuous extraction process presented in this Communication could be further developed to a process on an industrial scale and it presents certainly a cleaner technology than the currently used industrial processes. The green credentials of a continuous ionic liquid extraction process are mainly the non-volatility and non20 flammability of the ionic liquid, since the emission of odorous volatile components (diluents, modifier and extractant) are avoided. This leads to environmentally friendlier and healthier working conditions. The features of the Xstrata process can be compared with that of our continuous ionic liquid process. 25 Although the nickel concentration is much higher in the leach solution of the Xstrata process than in our experiments, a nickelrich feed will not have a huge influence on the results, because nickel is barely extracted. However, the extraction efficiency is affected by the cobalt concentration due to change in the viscosity 30 of the ionic liquid phase upon extraction of cobalt. Only relatively low cobalt loadings $\left(<20 \mathrm{~g} \mathrm{~L}^{-1}\right)$ can be used. The viscosity of the ionic liquid phase will ranges between 100 and $150 \mathrm{cP}$ after extraction, if the initial cobalt concentration in aqueous feed is similar to that of the Xstrata process $\left(11 \mathrm{~g} \mathrm{~L}^{-1}\right){ }^{17}$

35 However, the raffinate solutions of the Xstrata process are much more purified (about ten times higher) compared to our continuous ionic liquids process. Hence, our process still needs further optimization. This optimization includes introducing extra washing steps, which allows further removal of the nickel 40 impurities from the organic phase. As suggested earlier, the use of a second mixer settler in counter-current mode for cobalt extraction will further reduce the cobalt content in the nickel raffinate.

\section{${ }_{45}$ Conclusions}

The proof-of-principle of a continuous ionic liquid extraction process for the separation of metals has been given. Cobalt and nickel could be separated using the ionic liquid trihexyl(tetradecyl)phosphonium chloride $\left(\right.$ Cyphos $^{\circledR}$ IL 101) as 50 extraction phase. The setup with one extraction step, a washing step and three counter-current stripping steps gave pure cobalt $(>$ $99.8 \%$ ) and nickel (> 99.5\%) stream. After stripping, the ionic liquid phase was regenerated. We have shown that ionic liquids can be implemented in industrially applied solvent extraction 55 processes with an equal or even smaller number of mixer settler stages than the state-of-the-art industrial processes. The problems associated with the inherently higher viscosity of ionic liquid phases have been solved. Our process could be made competitive with the current industrially applied processes after applying 60 minor optimizations. The continuous ionic liquid extraction process offers a more sustainable approach to solvent extraction by eliminating volatile and odorous compounds. This leads to environmentally friendlier and healthier working conditions.

\section{Acknowledgements}

${ }_{65}$ This research was supported by the Flemish Institute for the Promotion of Innovation by Science and Technology (IWT Vlaanderen) via a Baekeland $\mathrm{PhD}$ fellowship to Sil Wellens (IWT 090272) and by Umicore Group Research. ICP-OES and TOC analyses were performed in the analytical laboratory of 70 Umicore Group Research.

\section{Notes and references}

${ }^{a}$ KU Leuven, Department of Chemistry, Celestijnenlaan 200F, bus 2404, B-3001 Heverlee, Belgium. E-mail:

Koen.Binnemans@chem.kuleuven.be

75 'Umicore, Group Research \& Development, Competence Area

Recycling and Extraction Technologies, Kasteelstraat 7, B-2250

Olen, Belgium.

1 J. Rydberg, M. Cox, C. Musikas and G. R. Choppin, in Solvent

80 Extraction: Principles and Practice, Marcel Dekker, Inc., New York, $2^{\text {nd }}$ edition, 2004.

2 T. Welton, Chem. Rev., 1999, 99, 2071-2083.

3 N. V. Plechkova and K. R. Seddon, Chem. Soc. Rev., 2008, 37, 123150.

854 A. P. Abbott, G. Frisch, S. J. Gurman, A. R. Hillman, J. Hartley, F. Holyoak and K. S. Ryder, Chem. Commun., 2011, 47, 10031-10033.

5 A. P. Abbott, G. Frisch, J. Hartley and K. S. Ryder, Green Chem., 2011, 13, 471-481.

6 J. G. Huddleston, H. D. Willauer, R. P. Swatloski, A. E. Visser and R.

$90 \quad$ D. Rogers, Chem. Commun., 1998, 1765-1766.

7 M. L. Dietz, Sep. Sci. Technol., 2006, 41, 2047-2063.

8 I. Billard, Chapter 256 - Ionic Liquids: New Hopes for Efficient Lanthanide/Actinide Extraction and Separation? In Handbook on the Physics and Chemistry of Rare Earths, ed. J. C. G. Bünzli and

95 V. Pescharsky, Elsevier, 2013, pp 213-273.

9 Z. Kolarik, Solvent Extr. Ion Exch., 2013, 31, 24-60.

10 A. Stojanovic and B. K. Keppler, Sep. Sci. Technol., 2012, 47, 189203.

11 P. R. Vasudeva Rao, K. A. Venkatesan, A. Rout, T. G. Srinivasan

100 and K. Nagarajan, Sep. Sci. Technol., 2012, 47, 204-222.

12 D. Parmentier, S. J. Metz and M. C. Kroon, Green Chem., 2013, 15, 205-209.

13 N. Papaiconomou, G. Vite, N. Goujon, J. M. Leveque and I. Billard, Green Chem., 2012, 14, 2050-2056.

10514 M. L. Dietz and J. A. Dzielawa, Chem. Commun., 2001, 2124-2125.

15 M. L. Dietz, J. A. Dzielawa, I. Laszak, B. A. Young and M. P. Jensen, Green Chem., 2003, 5, 682-685.

16 I. Billard, A. Ouadi and C. Gaillard, Dalton Trans., 2013, 42, 62036212.

11017 S. Wellens, B. Thijs and K. Binnemans, Green Chem., 2012, 14, 1657-1665. 
18 T. Vander Hoogerstraete, S. Wellens, K. Verachtert and K.

Binnemans, Green Chem., 2013, 15, 919-927.

19 K. Binnemans, P. T. Jones, B. Blanpain, T. Van Gerven, Y. Yang, 3 A. Walton and M. Buchert, J. Clean. Prod., 2013, 51, 1-22.

520 A. Stojanovic, Morgenbesser C, D. Kogelnig, R. Krachler and B. K. Keppler, Quaternary Ammonium and Phosphonium Ionic Liquids in Chemical and Environmental Engineering. In Ionic Liquids: Theory, Properties, New Approaches, ed. A. Kokorin, InTech, New York, 1 edn., 2011, pp 657-680.

1021 C. J. Bradaric, A. Downard, C. Kennedy, A. J. Robertson and Y. H. Zhou, Green Chem., 2003, 5, 143-152.

22 Ritcey G.M., Development of Industrial solvent extraction processes. In Principles and practices of solvent extraction, ed. J. 35 Rydberg, C. Musikas and G. R. Choppin, Marcel Dekker, New

$15 \quad$ York, $1^{\text {st }}$ edition, 1992, pp 449-510.

23 J. R. Trindade, Z. P. Visak, M. Blesic, I. M. Marrucho, J. A. P. Coutinho, J. N. C. Lopes and L. P. N. Rebelo, J. Phys. Chem. B, 2007, 111, 4737-4741.

24 J. Krockel and U. Kragl, Chem. Eng. Technol., 2003, 26, 1166-

201168.

25 K. Haerens, S. Van Deuren, E. Matthijs and B. Van der Bruggen, Green Chem., 2010, 12, 2182-2188.

26 F. Crundwell, M. Moats, V. Ramachandran, T. Robinson and W. G. Davenport, in Extractive Metallurgy of Nickel, Cobalt and Platinum

25 Group Metals, Elsevier, Amsterdam, 1st edition, 2011.

27 E. O. Stensholt, O. M. Dotterud, E. E. Henriksen, P. O. Ramsdal, F. Stalesen and E. Thune, Cim Bulletin, 2001, 94, 101-104. 